\title{
Opsoclonus associated with scrub typhus
}

自的

Supplemental data at www.neurology.org
A 64-year-old woman and a 40-year-old man (video on the Neurology ${ }^{\circledR}$ Web site at www.neurology.org) diagnosed with scrub typhus presented opsoclonus. Drowsiness and mild nuchal rigidity were observed, whereas cranial nerve dysfunction, limb weakness, and sensory loss were not. Brain MRI showed normal findings. The serum antibody titers to Orientia tsutsugamushi were 1:2,560. CSF cytology revealed white blood cell counts of 49 and $28 / \mathrm{mm}^{3}$ and protein levels of 102 and $91 \mathrm{mg} / \mathrm{dL}$.

Opsoclonus reflects an abnormality of the tonic inhibitory control of horizontal and vertical saccadic burst neurons exerted by "pause cells" in the parapontine reticular formation. ${ }^{1}$ It complicates various medical diseases, including viral infections, toxin, encephalitis, brain tumors, and paraneoplastic syndromes. ${ }^{2}$

\section{T.-S. Nam, MD, S.-M. Choi, MD, K.-H. Park, MD, M.-K. Kim, MD, K.-H. Cho, MD, Jeonnam and Gwangju, South Korea}

Address correspondence and reprint requests to Dr. Myeong-Kyu Kim, Department of Neurology, Chonnam National University Medical School, 8 Hak-dong, Dong-gu, Gwangju, 501-757, Korea; mkkim@chonnam.ac.kr

Received December 25, 2009. Accepted in final form February 19, 2010.

\section{REFERENCES}

1. Anderson NE, Budde-Steffen C, Rosenblum MK, et al. Opsoclonus, myoclonus, ataxia, and encephalopathy in adults with cancer: a distinct paraneoplastic syndrome. Medicine (Baltimore) 1988;67:100-109.

2. Hersh B, Dalmau J, Dangond F, Gultekin S, Geller E, Wen PY. Paraneoplastic opsoclonus-myoclonus associated with anti-Hu antibody. Neurology 1994;44:1754-1755. 


\title{
Neurology
}

\author{
Opsoclonus associated with scrub typhus \\ T.-S. Nam, S.-M. Choi, K.-H. Park, et al. \\ Neurology 2010;74;1925 \\ DOI 10.1212/WNL.0b013e3181e2438d
}

This information is current as of June 7, 2010

\section{Updated Information \& Services}

\section{Supplementary Material}

References

Citations

Subspecialty Collections

Permissions \& Licensing

\section{Reprints}

including high resolution figures, can be found at: http://n.neurology.org/content/74/23/1925.full

Supplementary material can be found at: http://n.neurology.org/content/suppl/2010/06/06/74.23.1925.DC1

This article cites 1 articles, 1 of which you can access for free at: http://n.neurology.org/content/74/23/1925.full\#ref-list-1

This article has been cited by 1 HighWire-hosted articles: http://n.neurology.org/content/74/23/1925.full\#\#otherarticles

This article, along with others on similar topics, appears in the following collection(s):

All Neuro-ophthalmology

http://n.neurology.org/cgi/collection/all_neuroophthalmology Meningitis

http://n.neurology.org/cgi/collection/meningitis

Myoclonus

http://n.neurology.org/cgi/collection/myoclonus

Information about reproducing this article in parts (figures,tables) or in its entirety can be found online at:

http://www.neurology.org/about/about_the_journal\#permissions

Information about ordering reprints can be found online:

http://n.neurology.org/subscribers/advertise

Neurology ${ }^{\circledR}$ is the official journal of the American Academy of Neurology. Published continuously since 1951, it is now a weekly with 48 issues per year. Copyright. All rights reserved. Print ISSN: 0028-3878. Online ISSN: 1526-632X.

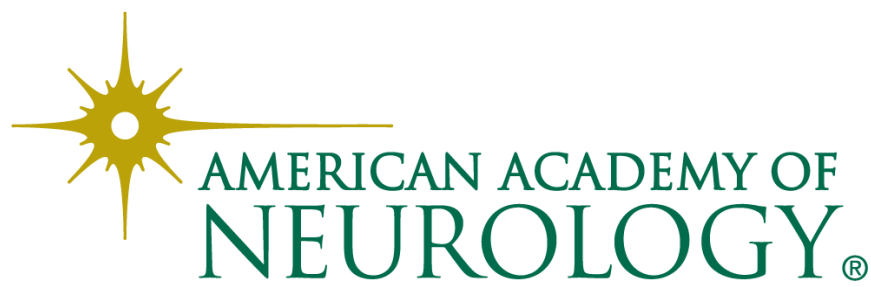

